\title{
Numerical solutions of electromagnetic wave model of fractional derivative using class of finite difference scheme
}

\author{
Vijay Patel $^{1}$ and Dhirendra Bahuguna ${ }^{1}$ \\ ${ }^{1}$ Indian Institute of Technology Kanpur
}

March 6, 2021

\begin{abstract}
In this article, a numerical scheme is introduced for solving the fractional partial differential equation (FPDE) arising from electromagnetic waves in dielectric media (EMWDM) by using an efficient class of finite difference methods. The numerical scheme is based on the Hermite formula. The Caputo's fractional derivatives in time are discretized by a finite difference scheme of order $\mathrm{O}\left(\left(\mathrm{k}^{\wedge}(4\right.\right.$-alpha $\left.)\right) \& \mathrm{O}\left(\mathrm{k}^{\wedge}(4\right.$-beta $\left.)\right), 1$
\end{abstract}

\section{Hosted file}

FDM for EMW.pdf available at https://authorea.com/users/299657/articles/512300-numericalsolutions-of-electromagnetic-wave-model-of-fractional-derivative-using-class-of-finitedifference-scheme 